[Stedman, G. (1997). Assessment, Accountability and the 1995 School Certificate Science Examination. New Zealand Annual Review of Education, $6,89-104]$

\section{Assessment, Accountability and the 1995 School Certificate Science Examination}

\section{GEOFFREY STEDMAN}

\section{Abstract:}

The discovery of serious flaws in the 1995 School Certificate science examination led to a vigorous public debate and to an extended discussion between the New Zealand Institute of Physics (NZIP) and the New Zealand Qualifications Authority (NZQA). This article documents these discussions from the point of view of the NZIP, and reflects upon accountability in the assessment of learning in science.

The School Certificate science examination of November, 1995, highlighted a number of assessment issues. Some were aired vigorously in the ensuing public debate; others were the subject of extended trans-institutional discussions. The latter included the New Zealand Institute of Physics (NZIP) and the New Zealand Qualifications Authority (NZQA). This article relates these discussions from an historical perspective as seen by the Council of NZIP, and attempts to summarise the circumstances as objectively as possible. The vigour and range of the public debate suggest that no coherent account entirely free from bias is possible. The following outline of events, therefore, does not claim to present the complete picture; it will necessarily emphasise those issues with which NZIP was directly concerned. Other discussion, not analysed here, extended to many other groups, in particular to several committees of the Royal Society of New Zealand (see Baker, 1996; Black, 1996).

The perspective adopted here highlights evidential rather than ideological matters. Beyond any issues of the educational trends in curriculum and assessment that may mould the setting and marking of
90 Geoffrey Stedman

School Certificate science papers (issues which are not of direct concern here), it is argued that safeguards on setting, marking and final evaluation of these 1995 examination papers were demonstrably inadequate.

NZIP restricted its public position to that of an expert witness, and this article makes a serious effort to retain that detachment. However, the subject matter inevitably touches on the educational ideologies which set this chain of events into New Zealand history; for example, the advantages and disadvantages of a constructivist approach to science education, or of unit standards for assessment (Matthews, 1995; Bell, 1995; Austin, 1996; Chamberlain, 1996). NZIP was publicly charged with what amounted to professional incompetence and with bias in educational ideology. This review mentions those charges only insofar as they complete the historical context.

Limitations on space preclude the giving of full quotations and referencing, but complete documentation exists for all exchanges, even though only a passing mention may be made in this article.

\section{The School Certificate Science Examination}

A School Certificate science examination was sat on 23 November 1995 by approximately 26,000 candidates across New Zealand. Three expressions of concern about the paper were of a general nature (not issues of a particular educational ideology). First, little study of science was needed to score well; one commentator argued that much of the paper amounted to an IQ test, rather than a test of scientific knowledge and ability (Mann, 1996). Secondly, because the examining panel had made a gallant attempt to frame the science questions in the context of relevant situations (compost heaps, food poisoning, exhaust physics, etc.), the situations under discussion were much too complex for an elementary analysis to be realistic. This led to a large number of variant, but defensible, answers, which in turn required both a degree of flexibility in the marking schedule and a level of insight by the markers which were unobtainable. Thirdly, in the middle of this generally confusing setting, certain parts of five of the questions contained quite significant scientific flaws (NZIP, 1996a)

\section{Two questions}

For the purposes of this article we consider two questions in the paper where scientific flaws were particularly conspicuous, and on which the greater part of the subsequent concern centred. 
Question FOUR-(a)5, p. 16

"A $250 \mathrm{~g}$ container of cherry stones fell $45 \mathrm{~m}$ to the ground from rest. It took 3 seconds to fall. (i) Calculate the speed at which it hit the ground. (ii) Calculate its force as it hit the ground."

Question SIX-(a)3, p. 21.

Richard and Scott, suffering from vomiting and diarrhoea, are carried out separately over farm tracks. "Use the information below to find out whether less work was done in moving Richard or Scott." The information is supplied in a table; the "force needed to carry" each is given, as is the length of each farm track.

The commonest interpretation of part (ii) of Question FOUR-(a) 5 was that it requests the force between the container and the ground on their collision. However, vital information which might have been used to provide a correct answer is not given. Adequate information to determine the duration of the contact with the ground and the degree of elasticity of the rebound is vital. If the box took a tenth of a second to sink to rest in mud, the average force could be 75 newtons ( 7.5 kilograms weight). If it bounced elastically off a cricket pitch in a hundredth of a second, the average force could be as much as 1500 newtons (150 kilograms weight). In short, part (ii) poses a question which is impossible to answer correctly.

An exemplary comment on Question SIX-(a) 3 was provided by one candidate in her examination answer:" $\mathrm{W}=\mathrm{F} . \mathrm{d}^{\prime \prime}$ (work is force times distance) "but this only applies in physics if the force applied is in the same direction as the movement, so they were not doing any work in this sense." The information given in the question was inadequate to solve the problem convincingly, since it lacked information to determine the altitude difference at the ends of each farm track. (The above response assumed these altitude differences to be zero.) Again, this was an impossible question.

\section{Examiners' expectations}

The examining panel anticipated and accepted the weight of the box (250 gram weight, or 2.5 newtons) as the correct answer to Question FOUR-(a)5(ii). As shown above, this is several orders of magnitude removed from reality. It suggests that parachutes are unnecessary, and that upon throwing oneself out of a high-rise building one can expect to land in armchair comfort (Stedman, 1995). One father explained the issue to his fourth form son by placing a potato on the kitchen scales. It registered as being 250 grams weight - the NZQA-approved answer. "Now hold it up and drop it," he said. The scale kicked up to well over 1 kilogram, approaching full scale. "Now," he asked, "what would the scale show if you dropped the potato from 45 metres?"

The examiners' anticipated answer to Question SIX-(a)3 was the product of force (weight) and distance (length of track), despite the fact that these two quantities have different directions. On this view, climbing Everest is a commuter's job, since a suburban cycle ride for 10 $\mathrm{km}$ would then require as much work as Sir Edmund Hillary expended in climbing Mt Everest (which is approximately $10 \mathrm{~km}$ high). Ignoring this requirement for parallel directions in force and distance is a classic school-student howler.

The obvious interpretation that can be placed on these questions (and one evident to numbers of able candidates) is that the examining panel displayed a seriously flawed understanding of elementary scientific concepts.

\section{Discussion of Problems in Setting the Paper}

\section{Initial exchanges between NZIP and NZQA}

NZIP was first alerted to problems with this examination by a concerned marker. It is unlikely that the matter would have been examined with despatch or in depth had not such contractors of NZQA decided that their public duty overrode any commitment to NZQA. The chief examination supervisor at one school had noticed the impossible demand in Question FOUR-(a)5 two weeks before the examination. When he contacted NZQA while there was time for a correction notice, his concern was met with indifference, disbelief, and rebuke. Such people rather deserve New Zealand's gratitude.

Professor C. W. Gardiner, a Fellow of the Royal Society of New Zealand and a member of NZIP Council, wrote a personal letter to NZQA in late November expressing and explaining his concern, in the hopes of acting in time to influence the marking process. After full consultation with the Council of NZIP, I wrote on their behalf to the Chief Executive Officer of NZQA (Mr D. Hood) on 6 December 1995, expanding on Professor Gardiner's concerns, and concluding: "The NZIP intends to make a public statement on this issue shortly. We are asking for your reply and cooperation in the hopes of being able to 
speak in a positive way, and to reassure all affected people that the problems with this examination paper and with the circumstances which led to them are fully recognised, and that professional and appropriate action is well in hand on these various and important issues."

A reply from the Chief Executive of NZQA dated 14 December supplied information on what was done in the marking process, but fell significantly short of the requested action, failing to acknowledge the gravity of the matter or to consider any need for further corrective measures for the benefit of affected candidates or for the advice of teachers. For example, it stated:"The Qualifications Authority has taken steps to ensure that no candidates were disadvantaged by the questions concerned" and "Candidates were not unduly troubled by the questions." (Other extracts are quoted below.) Such complacent phrases were evidence that NZQA would not initiate an in-depth examination of the concerns. Accordingly, the NZIP Council decided unanimously that it had a professional and public duty to issue a press statement.

\section{First national publicity}

The press statement issued by NZIP on 19 December 1995 included the following statement:

Several questions reflect a seriously flawed understanding of the most basic principles of the subject. The point is not that these questions are difficult. The point is that they are impossible. Any candidate attempting to answer these parts using the information given cannot give a correct answer and could reasonably be accused, as can the examiners themselves, of a fundamental ignorance of the basics of the subject. NZQA is forced to accept as correct answers which are outrageously wrong or quite irrelevant. NZIP believes that suppression of the matter now would only maximise the long-term damage. What of the candidates' misgivings about their attempts at such questions? Would publicity after results are announced be more welcome or effective?

To avoid imbalance, the 14 December letter from NZQA was faxed in full to all newspapers. Extracts from this statement were published prominently in major New Zealand daily newspapers. NZQA spokespersons were reported to respond with public statements such as: "science attracts various viewpoints, particularly in universities"; "universities have problems with science"; and "the science paper dealt with concepts, and it was not a physics examination." Later reported public statements from NZQA included: "the meaning of the flawed questions would only be unclear to those with an advanced knowledge of physics"; "a university physicist will be aware of some aspects of physics which a fifth-former will not be, and will naturally find some questions unanswerable at an advanced level"; and "despite the wording, candidates knew the question's intention."

This level of response seemed to endorse NZIP's pessimism about the effectiveness of dealing directly with NZQA. It stimulated widespread condemnation, including press editorials, lively newspaper correspondences, and several articles (Stedman, 1996a). One critical article, published in The Press, emphasised the universal character of science, and noted pointedly: "the force I would experience on meeting the ground [after a 45 metre fall] is brutally indifferent to all such niceties [of consideration of viewpoints and concepts]" (Stedman, 1995). On 27 August 1996 the New Zealand Skeptics bestowed their annual Bent Spoon award to NZQA.

\section{Discussion of Marking Problems}

\section{Second national publicity}

Under a commendable NZQA policy, marked examination scripts were returned to candidates in late January. A sample of these scripts was requested from candidates, and analysed by teachers and members of NZIP. These showed that the early warnings from both Professor Gardiner (which had been tabled at the marking panel meetings which finalised the marking schedule) and the NZIP itself, had not been taken into account. The impeccable answer quoted above by one pupil to Question SIX-(a)3 had been awarded 1 mark out of 5. The sample analysis showed that this was not an isolated incident; the NZQA-a pproved answers from the flawed marking schedule had clearly been applied rigorously, and deviations which were correct had been routinely penalised.

If such disadvantaged candidates were to have any chance of redress, the onus was on NZIP to apprise them of this new development, within the time-frame set by NZQA for requesting re-marking. (This deadline was later extended somewhat.) NZIP therefore lodged a second press statement on 2 February 1996, including: "The scripts now show that correct science was marked as 
wrong, while nonsense was marked as correct. Some of these candidates have been disadvantaged by 10 or more marks overall. This fully justifies the initial concerns of the Institute."

Reporters' analyses of this statement, often with comments from affected candidates and with NZQA reaction, were headlined on 3 February in all major daily newspapers, on One Network News and on TV3. Newspaper correspondence was re-invigorated. On 5 February the NZQA Publicity Officer (Ms K. Asare), an affected candidate, and I appeared on the "Holmes" show (prime-time investigative journalism). The Publicity Officer accepted that the NZIP concerns on the two questions detailed above were justified. Following the screening of this program, NZQA fielded a substantial number of enquiries and requests for re-marking.

Also on 5 February, Mr M. Steer, Team Manager of Examinations for NZQA, commenced discussions with me which ran at intervals for several weeks. A central topic was the nature of NZQA plans for administering the re-marking procedure. These proved to be very thorough, although still avoiding any reference to professional input from NZIP. Subsequently, NZIP circulated an analysis of the problems in the examination paper to secondary schools (NZIP, 1996).

\section{Ministerial discussion}

The then Minister of Education, Dr Lockwood Smith, concerned about the integrity of the examination, called a meeting of NZIP and NZQA delegates for 8 February. NZIP briefing papers included: "The NZQA seems to have placed undue reliance on the system of appointment of examiners, moderators, checkers, etc. The system failed. A tightly run ship still needs professional navigational aids from outside if it is to stay on course."

The Ministerial account of this meeting included: "The scientists wanted to check a revised marking schedule for the exam which the authority had agreed was flawed, and would be discussing this with the authority" (Smith, 1996). An NZIP summary (disseminated on 9 February to all parties), included: "The Minister and Authority accepted the need to have all returned scripts remarked thoroughly, according to a readjusted marking schedule which took account of all the [NZIP-] detailed concerns about particular questions. Mr Hood would communicate with the Institute concerning the readjusted marking schedule." The Chief Executive of NZQA sent a circular dated 9 February to school principals only, in which all discussion of the marking schedule was avoided and bounds regarded as irrelevant by the NZIP were set on the re-marking exercise: "Reconsideration will be to correct any errors made by markers. There is no evidence of greater marking inconsistency in the questions identified in the Institute's letter than elsewhere. We do not therefore expect any increased incidence of mark shifts in these questions." Accordingly, NZIP protested to NZQA over this misrepresentation of the NZIP concerns and the understandings of 8 February.

\section{Re-marking}

As part of the discussions with the NZQA Examinations Team, a joint statement by NZIP and NZQA was negotiated for release on 9 April (prior to the return of re-marked scripts, and before any NZIP inspection of these or of the marking schedule was permitted) with the aim of reassuring the public. However, this statement was never well publicised, the NZQA Publicity Office deciding not to release it. In the end, over 1300 scripts were re-marked; a pproximately 40 percent gained an increase in marks. NZIP analysis of some re-marked scripts confirmed that the Examinations Team plans had been effective, and that NZQA had now done as well as could be expected in these circumstances.

\section{Chief Marker's report and the marking schedule}

In late April, after the conclusion of the re-marking exercise, the long-awaited Chief Marker's Report and Marker's Schedule (NZQA, 1995) was released to schools and to NZIP, who had been assured that this report would not shirk any of the issues. However in critical areas this report proved to be a face-saving exercise, and in sum quite inadequate for guidance of teachers and future candidates. An NZIP analysis (24 May, 1996, unpublished) of the report in the section relating to Question FOUR-(a)5, for example, includes the following critical comment:

The Chief Marker states: "An error occurred in the wording ..." The major matter at stake [was rather] a clear failure to understand the fundamentals of Physics. The explanation given for the failure to use the "corrected wording" is itself open to major objection. The Chief Marker states, "The intention in putting "... as it hit the ground" was to test whether candidates considered that the time taken to fall was a factor in calculating 
force." This, a novelty in the discussion as far as NZIP is concerned, reads as another attempt to whitewash an ill-conceived question.

A second presidential report to NZIP members accordingly stated:

The School Certificate science exam incident highlights one aspect which I suggest is both noncontroversial and decisive. Since NZQA has roundly failed this exam (as a test of its quality control) on all fronts, the omens for the larger issues are bleak indeed. Even with our extensive professional advice, NZQA still cannot get its studied evaluation of one exam approximately right. What hope does it bring to the larger issues? Good teachers will struggle valiantly to make the effects of any imposed bureaucracy tolerable. But is the flawed work of weaker teachers to be put right this way? This exam incident shows that NZQA cannot do this. (Stedman, 1996b)

Direct negotiations with NZQA examinations personnel now appeared to have run their course.

\section{Direct NZIP Negotiations with Board of NZQA}

\section{School Certificate}

On 2 May 1996, Professor Gardiner and I met Sir Neil Waters, Chairman of the Board of NZQA, to discuss our concern on a number of the outstanding issues. NZIP followed this up on 27 May with a letter of appeal to the Board, documenting four outstanding concerns: the inadequacy of the Chief Marker's report of April 1996 as guidance to teachers; the misleading nature of the information NZQA gave about the scope of the re-marking; the failure of the NZQA Publicity Officer to honour NZQA's obligations to both NZIP and NZQA over the joint release; and the apparent lack of cooperation over the agreed involvement of an NZIP representative as consulting examiner. The Chairman of the Board asked Mr M. Murtagh to discuss the situation with me. In that discussion, on 5 June, only the fourth concern was resolved.

NZIP lodged a second appeal to the Board on 13 June 1996, including:

We cannot agree that what NZQA has done is reasonable even

in the circumstances, and we remain severely critical of the misleading information given to teachers and to candidates in such NZQA statements and releases. In particular we cannot condone the repeated attempts by NZQA personnel to separate the handling of matters of procedures and matters of content. This wished-for separation seems deeply embedded in the NZQA psyche, but is unsustainable in reality, as these issues indicate. Mr Murtagh explicitly denied that NZQA had any direct responsibility on professional matters related to examination paper or report content.

The reply from the Chairman of the Board, on 1 July 1996, although not directly discussing the outstanding concerns, included:

I do not, however, agree with your assertion that the Authority must take responsibility for "professional matters" connected with examination papers. It is not only impossible to do this without employing a large number of subject experts but is most undesirable and probably improper. Each examination is set on the subject curriculum - which is not the responsibility of the Authority - and needs to be "owned" by the sector concerned which is asked to supply the examiners and the moderators. The Authority certainly has the important task of appointing experts who know what they are about but it is not equipped, and nor should it be, to then impose its own decisions on the professional judgements of these people. Neither do I agree with your comments about the re-marking. Given that all the scripts were returned to candidates it seems to me that a complete re-mark to a new schedule would have been quite impossible. To mark just those who asked on an entirely new schedule would, it also seems to me, have been unfair. Under the circumstances I feel that the examiners did the best that they could. Clearly marking of the incorrect questions was changed and this, of course, was the point of giving candidates the option of applying for a reconsideration.

NZIP replied on 13 July 1996:

Then, we ask, who does take responsibility? The previous Minister of Education referred us to the Board of NZQA as the proper court of appeal. NZQA appoints the examiners confidentially and anonymously; they are therefore the NZQA examiners. Who protects the candidates from incompetent 
examiners? NZQA has an inescapable responsibility in these areas. NZQA cannot on the one hand deny its responsibility in this area and simultaneously claim to administer effective quality control over the related areas of national education. [On marking] our concern was that NZQA did not give inquirers a much fairer idea of what was entailed by re-marking. Emphasising that an entirely old (and discredited) schedule would be employed, with no clear statement to the effect that concerns about the incorrect physics would be considered, in practice misdirected the public.

NZIP also formally asked for the names of the examiners of the 1995 School Certificate science paper. The Chairman of the Board replied on 14 August, reiterating the Board position on the chief areas of concern, naming the Chief and Assistant Examiner, and advising that an external quality audit panel would review its examination processes, with one of the panel members being a senior professional officer from an overseas examination authority.

\section{Proposal for a National Standards Body}

In June 1996, some former members of the Science and Technology Advisory Group (STAG), itself a body set up by NZQA, submitted a proposal to the Board of NZQA to authorise setting up of the appropriate Science and Technology National Standards Body (NSB), for purposes such as the "development and review of unit standards and qualifications." The proposal interpreted these purposes as including formal definition of cross-institutional relativities implying the setting of standards from Levels 1 to 8 , that is, from school through tertiary education to postgraduate level training. The proposal did not contemplate the involvement of professionally competent organisations, and set no professional qualifications as criteria for NSB members, requiring of them only ideological compatibilities with NZQA and managerial ability.

In view of tardy and inadequate dissemination of the proposal and a looming deadline for public comment, NZIP issued its comment partly through a press statement of 20 August, 1996 (NZIP, 1996b), including:

It is inappropriate for NZQA to contemplate such authorisation. NZQA has no legal power to set up a national Standards Body with power to control all secondary and tertiary qualifications in this way. (Burrows, 1996)
It is inappropriate for NZQA to accredit its own educational authority group for advice on standards. The processes of authorisation and appeal must be separated. Otherwise, NZQA will have authorised a quasi-professional body so that the latter can in turn authorise what NZQA does in a professional context. Such bootstrapping of credibility smacks strongly of the procedures of confidence tricksters. The attempt to define all qualification standards and all relativities of secondary and tertiary education to postgraduate level is a delusion of grandeur. Such decisions would need full professional consultation with all existing professional organisations. It is frightening that such grandiose powers should be contemplated in such a professional vacuum. It is also ironic; NZQA has proved to be both incompetent and unwilling to maintain the most basic of professional standards. After long discussions with NZIP, NZQA and its Board still do not accept culpability for the 1995 School Certificate science paper (which was seriously flawed at an elementary level). NZQA and its Board also remain paralysed over the seriously misleading April 1996 report of the Chief Marker on that exam. It is irresponsible for a qualifications authority, whose main job is to "moderate assessment procedures", to deny responsibility for failure at a task it is charged to do, both by law and ministerial directive.

This concern was reported, though at different times and in different ways, by all major newspapers. As of this writing, the National Standards Body issue is still sub judice. The Royal Society and the Vice-Chancellors' Committee were among those professional bodies who also wrote to the Board of NZQA with concern over the NSB proposal. The present Minister of Education, Wyatt Creech, has since instructed NZQA to conduct dialogue and find a solution with which all parties "are comfortable."

\section{Overseas appraisal}

The fundamental problems highlighted by this historical account are not unique either to this examination or to New Zealand (Campbell, 1991). Qualifications authorities throughout the Western world have failed to earn a good standing in professional circles (Gagnon, 1996), and the proposed involvement of a representative of a sister organisation in an audit of the examinations operation, while of interest, is unlikely to 
resolve the issues raised here. The integrity of assessment methods in secondary-level science has proved to be highly contentious, even in Britain (Irwin, 1994). A summary of the above events in a UK physics bulletin (Stedman, 1996c) drew the comment from one British teacher (Warren, 1996): "I envy the people of New Zealand. Here, public and professional bodies have failed to make any effective stand against the most shocking abuses. Einstein wrote that 'authoritarian arrogance is the greatest enemy of truth.' This is certainly the case in science education."

\section{Conclusions}

Aspects of the position of NZQA in this affair deserve some sympathy, and fairness demands that these should be recorded.

First, the recency of the introduction of a new curriculum in science within the last two years, maaking this examination paper different in scope from earlier ones, became the source of some unnecessary confusion.

Secondly, this examination experience revealed a problem which (far from the nodding of some Homer) is as much the concern of the teaching profession as of NZQA. It would have been much less likely to occur had the standard of science teaching at lower levels in secondary schools been at an acceptable level. (The examining panel for this paper should have recognised that their work was inadequate.) That the situation, not only in New Zealand but throughout Western nations such as the United States and the UK, falls well short of this in the physical sciences (and physics in particular) is a continuing scandal (see, for example, Oughton, 1995). One useful spin-off of this incident is that the Ministry of Education has planned a study to obtain further information on the level of qualifications of teachers of physics and general science. Another is that an NZIP representative is now formally included as a consulting examiner for School Certificate science; however, this is at best a stop-gap measure in improving the quality of assessment in science.

Thirdly, any such public body for the setting and monitoring of standards is certain to be unpopular, and will find itself a ready and static target for many self-opinionated or discontented people and for vocal pressure groups. Although too often loyalty to colleagues was placed ahead of concern for the candidates, it is understandable that self-protection has become NZQA's standard response to criticism.
However the full history of this examination incident illustrates a problem which runs more deeply than mere siege mentality. For example, it should not have taken a second round of major national publicity for NZQA to admit publicly that even the most elementary concerns were justified. NZQA has been pressing the boundaries of its parliamentary mandate and is conducting experiments in assessment and certification in New Zealand education with missionary zeal. In doing so, NZQA has exacerbated its isolation, setting itself up as both judge and jury. Indeed, it can be argued that NZQA here is playing two basically incompatible roles. On the one hand, it has insisted that its function is purely managerial, and therefore rejects its accountability for scientific errors in its examinations, emphasising that all its (managerial) criteria were adequately met by these same papers. On the other, NZQA is a public body which insists on total control under the highest security of the whole of the examination process, including the appointment of examiners as its contractors (who retained anonymity until mid-1996). The quotations above show NZQA speaking with two voices even at Board level: refusing to accept culpability for School Certificate science problems, and at the same time actively pursuing the self-accreditation of a self-appointed National Standards Body to advise it in professionally significant matters. NZQA's avoidance of independent professional judgements and its reliance on internal managerial guidelines thus constitute a managerial ideology which it has applied holistically to bootstrap its own quality control. Should an examining panel perform incompetently, no external feedback system (such as a link with external professional bodies like the Academy of the Royal Society of New Zealand) exists which could alert NZQA to this. When the blind lead the blind, the occasional tumble in the ditch is inevitable.

In sum, there are some important lessons to be drawn for the future from the 1995 School Certificate science examination incident:

- There is an urgent need to attract well-qualified teachers to teach science in New Zealand classrooms, both primary and secondary. The problem is particularly acute in physics. A survey of the qualifications of those currently teaching science in New Zealand schools is a necessary first step in this process;

- Improved screening procedures need to be found to ensure that School Certificate examiners are not only experienced classroom teachers and competent in assessment techniques, but also wellqualified in the disciplines which they are examining; moderating 
panels in science likewise should include professional scientists who take their responsibilities seriously in checking and validating draft examination papers;

- While NZQA is to be commended in its openness in returning all marked examination scripts to candidates, new mechanisms need to be put in place to ensure that errors, once detected, can be admitted and corrected. Professionally acceptable goals cannot be secured by purely managerial techniques and criteria. NZIP was forced to use the public media on three occasions over this incident precisely because no other adequate feedback mechanism existed;

- There are dangers in confusion of roles if a body such as NZQA is empowered to appoint its own advisory board to deal with national standards. As an organisation for the management of the mechanics of national examinations, NZQA performs an essential task well. But its present managerial approach has been shown to be fundamentally inappropriate and inadequate for the oversight of professional matters. Along with a clarification of its roles, some way must be found for NZQA both to obtain and to accept independent professional feedback and advice, if its public accountability is not to be severely compromised in the future.

\section{Acknowledgements}

I am most grateful for the input of all Council and NZIP members, and others too numerous to name who have assisted in the evaluation of this examination. I also would like to thank the NZQA Examinations Team for their integrity and commitment in discussions.

\section{References}

Austin, L. (1996, May). Making sense of learning science in New Zealand. Chem NZ, 63. (NZIC Bulletin).

Baker, R. (1996, April). Editorial. New Zealand Association of Science Educators Newsletter, Term 2, 2-3.

Bell, B. (1995). Response to Challenging New Zealand Science Education by Michael R. Matthews. Hamilton: University of Waikato Centre for Science, Mathematics and Technology Education Research.

Black, P. M. (1996). Science and technology education, new curricula, qualifications framework and unit standards. Royal Society discussion document for Fellows' AGM, 20 November 1996.
Burrows, J. (1996, August 30-September 5). NZ Education Review, p. 3. Campbell, P. (1991, A pril). Support teacher retraining. Physics World, 4, 3. Chamberlain, J. (1996, September). Framed! Has the NZQA hoodwinked a nation? North and South, 112-122.

Gagnon, P. (1996, December). What should children learn? Atlantic Monthly, 65-74.

Irwin, M. (1994, May). Curriculum, assessment and qualifications. Report prepared for the Education Forum.

Mann, B. (1996). What was wrong with the 1995 School Certificate Science Exam? NZ Science Teacher, 81, 5-6.

Matthews, M. R. (1995). Challenging New Zealand science education. Palmerston North: Dunmore Press.

NZ Institute of Physics (NZIP) (1996a, February). 1995 School Certificate Science Examination. NZ Association of Science Educators Newsletter, Term 1.

NZ Institute of Physics (1996b). NZPA Press release of 20 August. $<$ www.phys.canterbury.ac.nz/nzip/>

NZ Qualifications Authority. (1995). School Certificate Science, No. 067 Chief Marker's Report and Marker's Schedule 1995. Wellington: NZQA.

Oughton, T. (1995). Knowledge and pedagogy: Critical dimensions in the training of chemistry teachers. Chem NZ, 61, 5-15.

Smith, L. (1996). NZPA Press Release of 8 February, 17-37NZ.

Stedman, G. E. (1995, December 27). The flaws that made nonsense of parts of the SC science exam. The Press, Christchurch.

Stedman, G. E. (1996a. No science institutes? No accountability. Aust. $\mathcal{E}$ NZ Physicist, 33(2), 2.

Stedman, G. E. (1996b). NZQA examination saga. Aust. \& NZ Physicist, 33(7), 134-135.

Stedman, G. E. (1996c, October). Exam trouble in New Zealand, Physics World, 13.

Warren, J. (1996, November). State of confusion, Physics World, 15.

\section{The author}

Geoff Stedman is Professor of Physics at the University of Canterbury, a Fellow of the Royal Society of New Zealand, and was President of the New Zealand Institute of Physics from September 1994 to August 1996. 